Pacific Journal of 


\title{
FURTHER REMARKS ON IDEALS OF THE PRINCIPAL CLASS
}

\author{
EDWARD D. DAVIS
}

\begin{abstract}
In a previous paper on this subject, the author gave a new proof of the theorem of "analytic independence of systems of parameters". The methods used can be applied to prove a converse result. Hence: An ideal of a Noetherian ring is of the principal class if, and only if, it is generated by an analytically independent set.
\end{abstract}

The subset $\left\{z_{1}, \cdots, z_{n}\right\}$ of a ring $R-R$ is commutative with $1 \neq 0$, as are all rings here considered-is said to be analytically independent provided that $\left(z_{1}, \cdots, z_{n}\right) R$ is not the unit ideal, and for every homogeneous $f$ in the polynomial ring $R\left[X_{1}, \cdots, X_{n}\right]$ such that $f\left(z_{1}, \cdots, z_{n}\right)=0$, the coefficients of $f$ lie in the radical of $\left(z_{1}, \cdots, z_{n}\right) R$. Now let $I$ be a nonunit ideal of $R$ generated by the set $\left\{x, x_{1}, \cdots, x_{n}\right\}$, with $x$ not a divisor of zero, and let $Q$ denote the kernel of the $R$-homomorphism $R\left[X_{1}, \cdots, X_{n}\right] \rightarrow S=R\left[x_{1} / x, \cdots x_{n} / x\right]$ determined by $X_{i} \rightarrow x_{i} / x$. (We regard $S$ as a subring of the full ring of quotients of $R$.) A completely elementary fact is that $\left\{x, x_{1}, \cdots, x_{n}\right\}$ is analytically independent if, and only if, for every prime ideal $P$ of $R$ containing $I$, $P R\left[X_{1}, \cdots, X_{n}\right]$ contains $Q$ (see preliminary remarks of [1]). Using this fact we gave in [1] a new proof of the theorem of "analytic independence of systems of parameters": If $R$ is Noetherian and I is of height $n+1$, then $\left\{x, x_{1}, \cdots, x_{n}\right\}$ is analytically independent. In considering a question raised by Professor E. Kunz, it come to light that the methods of [1] can be used to prove the converse result:

Proposition 1. If $R$ is Noetherian and $\left\{x, x_{1}, \cdots, x_{n}\right\}$ is analytically independent, then height $(I)=n+1$.

Lemma 1. If $P$ is a prime ideal of $R$ containing $I$, then $P S$ is a prime ideal of $S, P S \cap R=P$, and $S / P S$ is $(R / P)$-isomorphic to $(R / P)\left[X_{1}, \cdots, X_{n}\right]$

Lemma 2. Let $M$ be a prime ideal of $S$, and let $P=M \cap R$. Then height $(P) \geqq \operatorname{tr}$.dg. $[S / M: R / P]+$ height $(M)$.

Proof of the lemmas. The facts stated in Lemma 1 are proved in the preliminary remarks of [1]. Lemma 2 is well known in the case of $R$ an integral domain (see, for example, Appendix 1 of Zariski- 
Samuel vol. II [2]); we generalize to the case at hand as follows. Let $M_{0}$ be a minimal prime ideal of $S$ contained in $M$ such that height $\left(M / M_{0}\right)=$ height $(M)$, and let $P_{0}=R \cap M_{0}$. Observe that $S / M_{0}$ and $R / P_{0}$ have the same quotient field, namely the quotient field of $K / N_{0}$, where $K$ is the full ring of quotients of $R$, and $N_{0}$ is the unique prime ideal of $K$ lying over $M_{0}$ (and $P_{0}$ ). Hence, using the integral domain result, we have:

$$
\text { height } \begin{aligned}
(P) & \geqq \text { height }\left(P / P_{0}\right) \\
& \geqq \operatorname{tr} . \operatorname{dg} .\left[S / M_{0} / M / M_{0}: R / P_{\mathrm{c}} / P / P_{0}\right]+\text { height }\left(M / M_{0}\right) \\
& \geqq \operatorname{tr} . \operatorname{dg} .[S / M: R / P]+\text { height }(M) .
\end{aligned}
$$

Proof of Proposition 1. Let $P$ be a minimal prime component of $I$. We must show that height $(P) \geqq n+1$, for it is well known that height $(P) \leqq n+1$. Now let $M=P S$. Lemma 1 says: $M$ is a prime ideal, $M \cap R=P$, and $S / M$ is a polynomial ring in $n$ variables over $R / P$. From these facts and Lemma 2 we have:

height $(P) \geqq \operatorname{tr} . \operatorname{dg} .[S / M: R / P]+$ height $(M)=n+$ height $(M)$.

Since $M$ contains $x$, which is not a divisor of zero, height $(M) \geqq 1$ (actually height $(M)=1$ ). Thus height $(P) \geqq n+1$.

Corollary. An ideal generated by an analytically independent subset of a Noetherian ring is of height equal to the cardinality of that set.

Proof. Let $A, J$ and $\left\{x_{1}, \cdots, x_{n}\right\}$ be the ring, ideal and analytically independent set in question. Let $R=A[x]$, where $x$ is an indeterminate over $A$, and let $I=\left(x, x_{1}, \cdots, x_{n}\right) R$. It is clear that height $(I)=$ height $(J)+1$. Hence it suffices to prove that height $(I)=n+1$. It is notationally somewhat bothersome, but completely straightforward to verify that $\left\{x, x_{1}, \cdots, x_{n}\right\}$ is an analytically independent subset of $R$. Proposition 1 now applies.

REMARK. One can prove this corollary in a somewhat less elementary way. Localize $A$ at a minimal prime component $P$ of $J$ and then complete. The canonical image of the set $\left\{x_{1}, \cdots, x_{n}\right\}$ is an analytically independent subset of the complete ring and the image of $J$ is primary for the maximal ideal. Then conclude, using Cohen's structure theory for complete local rings, that the complete ring is an integral extension of a ring of dimension at least $n$. Thus dimension $\left(A_{P}\right) \geqq n$. The "characteristic equal" and "characteristic unequal" cases must be treated separately.

This corollary and the theorem of "analytic independence of systems of parameters" (proved in many places, among them in Corol- 
lary 1 to Proposition 1 of [1]) comprise the following theorem.

THEOREM. An ideal of a Noetherian ring is of the principal class if, and only if, it is generated by an analytically independent set. Furthermore, the height of an ideal of the principal class is equal to the cardinality of any analytically independent set of generators (which then must be a minimal generating set).

And of special interest is the following criterion.

Corollary. A subset consisting of dimension $(R)$ elements of a local ring $R$ is a system of parameters of $R$ if, and only if, that subset is analytically independent.

In the notation of the discussion immediately preceding the statement of Proposition 1, this proposition combines with Proposition 1 of [1] to say:

Proposition 2. The following statements are equivalent. (1) Height $(I)=n+1$. (2) $\left\{x, x_{1}, \cdots, x_{n}\right\}$ is analytically independent. (3) The radicals of $Q$ and the ideal generated by $\left\{x X_{1}-x_{1}, \cdots, x X_{n}-x_{n}\right\}$ coincide.

And in the special case that $R$ is an integral domain we have:

Proposition 2'. Statements (1) and (2) of Proposition 2 are equivalent to: $\left(3^{\prime}\right) Q$ is the radical of the ideal generated by $\left\{x X_{1}-x_{1}, \cdots, x X_{n}-x_{n}\right\}$.

\section{REFERENCES}

1. E. D. Davis, Ideals of the principal class, $R$-sequences and a certain monoidal transformation, Pacific J. Math. 20 (1967), 197-205.

2. O. Zariski and P. Samuel, Commutative Algebra Volume II, Van Nostrand, Princeton, 1960 .

Received October 31, 1967. Supported in part by the National Science Foundation under Grant GP-6388.

Purdue University

State University of New York at Albany

(Present address) 



\section{PACIFIC JOURNAL OF MATHEMATICS}

EDITORS

H. ROYDEN

Stanford University

Stanford, California

R. R. Phelps

University of Washington

Seattle, Washington 98105
J. DugundJI

Department of Mathematics

University of Southern California

Los Angeles, California 90007

\section{RICHARD ARENS}

University of California

Los Angeles, California 90024

\section{ASSOCIATE EDITORS}
E. F. BeCKENBACH
B. H. NeUmanN
F. WOLF
K. YOSIDA

\section{SUPPORTING INSTITUTIONS}

UNIVERSITY OF BRITISH COLUMBIA CALIFORNIA INSTITUTE OF TECHNOLOGY UNIVERSITY OF CALIFORNIA MONTANA STATE UNIVERSITY UNIVERSITY OF NEVADA NEW MEXICO STATE UNIVERSITY OREGON STATE UNIVERSITY UNIVERSITY OF OREGON OSAKA UNIVERSITY UNIVERSITY OF SOUTHERN CALIFORNIA
STANFORD UNIVERSITY UNIVERSITY OF TOKYO UNIVERSITY OF UTAH WASHINGTON STATE UNIVERSITY UNIVERSITY OF WASHINGTON

AMERICAN MATHEMATICAL SOCIETY CHEVRON RESEARCH CORPORATION TRW SYSTEMS NAVAL WEAPONS CENTER 


\section{Pacific Journal of Mathematics \\ Vol. 27, No. $1 \quad$ January, 1968}

Willard Ellis Baxter, On rings with proper involution ............... 1

Donald John Charles Bures, Tensor products of $W^{*}$-algebras........... 13

James Calvert, Integral inequalities involving second order derivatives . . . . 39

Edward Dewey Davis, Further remarks on ideals of the principal class.... 49

Le Baron O. Ferguson, Uniform approximation by polynomials with integral

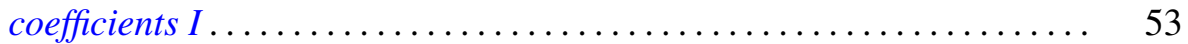

Francis James Flanigan, Algebraic geography: Varieties of structure

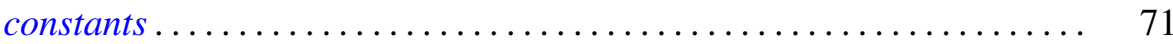

Denis Ragan Floyd, On QF -1 algebras ..................... 81

David Scott Geiger, Closed systems of functions and predicates ......... 95

Delma Joseph Hebert, Jr. and Howard E. Lacey, On supports of regular Borel measures ................................... 101

Martin Edward Price, On the variation of the Bernstein polynomials of a function of unbounded variation ........................ 119

Louise Arakelian Raphael, On a characterization of infinite complex matrices mapping the space of analytic sequences into itself........ 123

Louis Jackson Ratliff, Jr., A characterization of analytically unramified

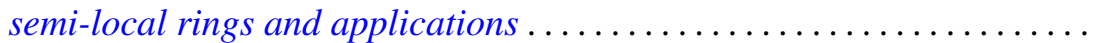

S. A. E. Sherif, A Tauberian relation between the Borel and the Lototsky transforms of series ................................ 145

Robert C. Sine, Geometric theory of a single Markov operator .......... 155

Armond E. Spencer, Maximal nonnormal chains in finite groups......... 167

Li Pi Su, Algebraic properties of certain rings of continuous functions .... 175

G. P. Szegô, A theorem of Rolle's type in $E^{n}$ for functions of the class $C^{1} \ldots 193$

Giovanni Viglino, A co-topological application to minimal spaces ........ 197

B. R. Wenner, Dimension on boundaries of $\varepsilon$-spheres ............... 201 